\title{
Synaptic Imbalance, Stereotypies, and Impaired Social Interactions in Mice with Altered Neuroligin 2 Expression
}

\author{
Rochelle M. Hines, ${ }^{1 \star}$ Longjun Wu ${ }^{2 *}$ Dustin J. Hines, ${ }^{1}$ Hendrik Steenland, ${ }^{2}$ Souraya Mansour, ${ }^{1}$ Regina Dahlhaus, ${ }^{1}$ \\ Roshni R. Singaraja, ${ }^{3}$ Xiaoyan Cao, ${ }^{2}$ Esther Sammler, ${ }^{4}$ Sheriar G. Hormuzdi, ${ }^{4}$ Min Zhuo, ${ }^{2}$ and Alaa El-Husseini ${ }^{1}$ \\ ${ }^{1}$ Department of Psychiatry, Brain Research Centre, Faculty of Medicine, University of British Columbia, Vancouver, British Columbia, Canada V6T 2B5, \\ ${ }^{2}$ Department of Physiology, Faculty of Medicine, University of Toronto, Toronto, Ontario, Canada M5S 1A8, ${ }^{3}$ Department of Medical Genetics, Centre for \\ Molecular Medicine and Therapeutics, University of British Columbia, Vancouver, British Columbia, Canada V5Z 4H4, and ${ }^{4}$ Department of Neurology, \\ Ninewells Hospital and Medical School, University of Dundee, Dundee DD1 9SY, United Kingdom
}

The level of excitation in the brain is kept under control through inhibitory signals mainly exerted by GABA neurons. However, the molecular machinery that regulates the balance between excitation and inhibition (E/I) remains unclear. Candidate molecules implicated in this process are neuroligin $(\mathrm{NL})$ adhesion molecules, which are differentially enriched at either excitatory or inhibitory contacts. In this study, we use transgenic mouse models expressing NL1 or NL2 to examine whether enhanced expression of specific NLs results in synaptic imbalance and altered neuronal excitability and animal behavior. Our analysis reveals several abnormalities selectively manifested in transgenic mice with enhanced expression of NL2 but not NL1. A small change in NL2 expression results in enlarged synaptic contact size and vesicle reserve pool in frontal cortex synapses and an overall reduction in the E/I ratio. The frequency of miniature inhibitory synaptic currents was also found to be increased in the frontal cortex of transgenic NL2 mice. These animals also manifested stereotyped jumping behavior, anxiety, impaired social interactions, and enhanced incidence of spike-wave discharges, as depicted by EEG analysis in freely moving animals. These findings may provide the neural basis for $\mathrm{E} / \mathrm{I}$ imbalance and altered behavior associated with neurodevelopmental disorders.

Key words: neuroligin; transgenic; synapse; excitatory/inhibitory ratio; neurodevelopmental disorder; autism

\section{Introduction}

Synapse maturation is a critical step in the generation of the complex neuronal networks of the CNS (Waites et al., 2005). Homeostatic control has been suggested to regulate neuronal function through synaptic efficacy, strength, and membrane excitability (Turrigiano and Nelson, 2004). The importance of tight regulation of synapses can be gleaned from the number of disorders arising from alterations to synapses (Holmes and McCabe, 2001; Zoghbi, 2003).

Neuroligin (NL) adhesion molecules and their presynaptic binding partners, neurexins (Nrxs), are involved in regulating excitatory and inhibitory synapse function. NL function at the

\footnotetext{
Received Jan. 4, 2008; revised April 29, 2008; accepted April 30, 2008.

This work was supported by Canadian Institutes for Health Research (CIHR) Grant 20 R90479 (A.E.-H.), the Michael Smith Foundation for Health Research (MSFHR) Grant 20 R52464 (A.E.-H.), and the EJLB Foundation and Neuroscience Canada. A.E.-H. is an MSFHR senior scholar. R.M.H. is supported by CIHR and MSFHR doctoral scholarships. M.Z. is supported by grants from the CIHR, the EJLB-CIHR Michael Smith Chair in Neurosciences and Menta Health, and the Canada Research Chair. L.-J.W. is supported by postdoctoral Fellowship from CIHR and Fragile X Research Foundation of Canada. S.G.H. is supported by The Wellcome Trust Grant 078791 . We thank Jennifer Wittmer for microinjection and assistance with ovary transplants and Kimberly Gerrow for her assistance in neurona cell culture preparation. We also thank Drs. Yu Tian Wang, Brian MacVicar, and Tim Murphy for the valuable comments and suggestions. This work is dedicated to Dr. Alaa El-Husseini, a motivating and inspiring mentor and colleague. May he continue to inspire us.

*R.M.H. and L.W. contributed equally to this work.

Correspondence should be addressed to Rochelle M. Hines, 2255 Wesbrook Mall, University of British Columbia, Vancouver, British Columbia, Canada V6T 1Z3. E-mail: rbruneau@interchange.ubc.ca.

DOI:10.1523/JNEUROSCI.0032-08.2008

Copyright $\odot 2008$ Society for Neuroscience $\quad$ 0270-6474/08/286055-13\$15.00/0
}

synapse is modulated by alternative splicing and association with binding partners (Ichtchenko et al., 1995; Irie et al., 1997; Prange et al., 2004; Boucard et al., 2005; Levinson et al., 2005; Chih et al., 2006; Graf et al., 2006). Consistent with a fundamental role for NLs in synapse maturation, a reduction in presynaptic terminal content, but not number, has been observed in NL1-3 triple knock-out mice (Varoqueaux et al., 2006).

NLs are enriched at either excitatory $(\mathrm{NL} 1,3)$ or inhibitory (NL2) synapses (Song et al., 1999; Graf et al., 2004; Varoqueaux et al., 2004; Chih et al., 2005; Levinson et al., 2005; Chubykin et al., 2007). Despite their specific localization, in vitro studies indicate that NLs can induce both excitatory and inhibitory presynaptic specializations (Scheiffele et al., 2000; Graf et al., 2004; Prange et al., 2004; Chih et al., 2005; Levinson et al., 2005; Gerrow et al., 2006). The ability of NLs to regulate excitatory and inhibitory synapses led to the proposal that NLs may comprise the molecular machinery that maintains the ratio of excitation to inhibition (E/I ratio) (Cline, 2005; Levinson and El-Husseini, 2005). Work on cultured neurons shows that abnormal targeting of NLs to particular synapse types alters the E/I ratio (Levinson and ElHusseini, 2005; Levinson et al., 2005). Analysis of acute slices from NL knock-out mice also demonstrated that specific NLs differentially affect excitatory and inhibitory synapse function (Chubykin et al., 2007). These findings led to the question of whether altered expression of NLs could induce synaptic imbalance in vivo, leading to dysfunction of the CNS. 
An important link to CNS disorders was recently revealed when mutations in synaptic proteins were found to be associated with autism, a neurodevelopmental disorder characterized by repetitive/stereotyped behavior, varying degrees of abnormality in communication ability, and social interactions, along with high incidence of seizure (Konstantareas and Homatidis, 1999; Auranen et al., 2002; Tuchman and Rapin, 2002; Jamain et al., 2003; Rubenstein and Merzenich, 2003; Zoghbi, 2003; Laumonnier et al., 2004; Lisé and ElHusseini, 2006; Christ et al., 2007; Dover and Le Couteur, 2007; Garber, 2007; Rutherford et al., 2007). Rearrangements of chromosomal regions harboring NL1,2, and mutations in NL3,4 have been detected in families with autism. One particular NL3 mutation associated with autism, Arg451Cys, when introduced into mice, leads to enhanced inhibition and impaired social interactions (Tabuchi et al., 2007). Single-copy chromosomal deletion of a region containing $\alpha / \beta$-Nrxs in families with autism demonstrates the influence of changes in gene dose in autism (Szatmari et al., 2007). In addition to single gene alterations, recent work has shown that many autistic patients have novel deletions and duplications in their genomes (Sebat et al., 2007). Thus, both reduced and enhanced expression of affected genes can contribute to the manifestation of autism.

Both loss- and gain-of-function studies indicate that altered of amounts of NLs result in aberrant synapse maturation and altered neuronal excitability. It remains unclear, however, whether changes in the expression of single NLs in vivo will disturb the E/I balance and result in behavioral deficits. In the present study, we use transgenic ( $\mathrm{Tg}$ ) mice to examine whether expression of specific NLs results in synaptic imbalance and altered neuronal excitability in vivo. Our results reveal that enhanced expression of NL2 induces aberrant synapse maturation and altered neuronal excitability, leading to behavioral deficits.

\section{Materials and Methods}

Generation and genotyping of transgenic mice. NL1 and NL2 transgenes were expressed under control of the Thyl promoter for neuron-specific expression (Fig. 1A). Germ-line transmission of the transgenes was detected using PCR (supplemental Fig. $1 A$, available at www.jneurosci.org as supplemental material). For details of mouse generation and genotyping, see supplemental Methods (available at www.jneurosci.org as supplemental material).

Western blotting. Whole-brain lysates were prepared as described previously (Levinson et al., 2005). Briefly, extracted tissues were homogenized in $3 \mathrm{ml} / \mathrm{g}$ HEPES buffer, and cell debris was removed by centrifugation at $16,000 \times g$ at $4^{\circ} \mathrm{C}$ for $1 \mathrm{~h}$. Obtained supernatants were subjected to SDS-PAGE and analyzed by immunoblotting. Coomassie staining served to assess the protein loaded for each sample. For antibodies used, see supplemental Methods (available at www.jneurosci.org as supplemental material).

Behavioral assessments. All assessments of behavior were conducted by experimenters and observers blinded to the genotype of the animal. Before testing, animals used for all behavior experiments were arranged into matched sets containing at least one wild type (WT) and at least one transgenic littermate that were housed together (minimum of three per cage). These matched sets originated from three to four litters from distinct parental mating pairs. Individuals within sets (including wild type and TgNL2) were tested in the same day, and additional sets were tested at approximately the same time of day, on a subsequent day if required.

Preliminary screen. The preliminary screen were based on the modified SHIRPA protocol used by European Mouse Phenotyping Resource of Standardized Screens (EMPReSS) designed to evaluate the basic phenotype of transgenic mouse strains (Brown et al., 2005, 2006). For details of the scoring and methods of the phenotype screen, see supplemental Methods (available at www.jneurosci.org as supplemental material).

Open field behavior. The open field apparatus was based on that used in the EMPReSS resource (Brown et al., 2005, 2006). Open field behavior of mice was assessed using the Noldus Ethovision Tracking system from video recordings taken from above. Results from tracking analysis were analyzed using ANOVA to compare means.

Assessment of anxiety-like behaviors. Protocols for both the light/dark exploration test and the elevated plus maze were based on those used by Holmes et al. (2002, 2003). Video recordings of test sessions were digitized and manually assessed by a genotype-blinded observer to quantify number of transitions between the light and dark compartments, and the total time spent in the light and dark compartments (light-dark), or the number of entries (all four paws into an arm) and time spent in open and closed arms (elevated plus). For details of anxiety testing, see supplemental Methods (available at www.jneurosci.org as supplemental material). 
Social behavior assessments. The reciprocal social interaction paradigm was based on that used in previous studies (Tabuchi et al., 2007) and involved the introduction of a juvenile ( 6 weeks old) FVB male and either a wild-type or TgNL2.6 mouse into a neutral environment. Video recordings of $5 \mathrm{~min}$ interaction session were then manually scored by a blinded observer for interaction parameters of total time, average length, total number, and proportion of initiations.

Social approach behavior was assessed in an apparatus modeled after that used by Dr. J. Crawley's group (Moy et al., 2004; Nadler et al., 2004). Video recordings were assessed using the Noldus Ethovision Tracking system, and parameters, including time in zone, number of rears in zone, and speed traveled in zone, were compared. For more details on both the reciprocal social interaction and social approach behavior, see supplemental Methods (available at www.jneurosci.org as supplemental material).

In situ hybridization. In situ hybridization experiments were performed on postnatal day 28 (P28) mice as described previously (Wisden and Morris, 2002). For details of in situ hybridization, see supplemental Methods (available at www.jneurosci.org as supplemental material).

Immunohistochemistry. For histology and immunohistochemistry (IHC), animals were either transcardially perfused with a $4 \%$ solution of paraformaldehyde in PBS (nonfluorescent IHC) or brains were harvested fresh and flash frozen in OCT embedding medium in liquid nitrogen cooled isopentane (fluorescent synaptic protein IHC). Immunostaining and colocalization was quantified using Northern eclipse, and results were analyzed using $t$ tests to compare means. For antibodies used and additional details, see supplemental Methods (available at www. jneurosci.org as supplemental material).

Electron microscopy. Tissue for electron microscopy was harvested fresh and cut using a vibratome in room temperature artificial CSF (ACSF), followed by rapid fixation in $6 \%$ glutaraldehyde, $1 \%$ paraformaldehyde, $2 \mathrm{~mm} \mathrm{CaCl}$, and $4 \mathrm{mM} \mathrm{MgCl}_{2}$ in $0.1 \mathrm{M}$ cacodylate buffer. Results of synapse assessments were compared using ANOVA. For details of electron microscopy assessments, see supplemental Methods (available at www.jneurosci.org as supplemental material).

Whole-cell patch-clamp recordings. Coronal slices of the frontal cortex $(300 \mu \mathrm{m})$ were prepared using routine methods as described previously (Wu et al., 2007). For details of slice preparation and recording, see supplemental Methods (available at www.jneurosci.org as supplemental material).

In vivo electroencephalogram. Surgery was performed on 10 TgNL2 and five wild-type mice (12-21 weeks old) for electroencephalogram (EEG) studies. For details of EEG surgery, recording, and analysis, see supplemental Methods (available at www.jneurosci.org as supplemental material).

Statistical methods. Results from experiments comparing wild-type controls with TgNL2.6 strains were analyzed by $t$ tests to compare means. In the case of the social interaction test, in which $t$ tests were applied to four measures, a Bonferroni's multiple testing correction was calculated by dividing the standard significance level $(0.05)$ by the number of $t$ tests used (four), resulting in a Bonferroni's corrected level of 0.0125. Experiments comparing wild-type, TgNL2.6, and TgNL2.7, or for the threechambered social interaction paradigm, results were analyzed using ANOVA. The least squares difference post hoc test was applied to significant ANOVA comparisons. All statistical analyses were calculated using SPSS software.

\section{Results}

\section{Limb clasping reveals a neurological phenotype in mice expressing neuroligin 2 that is not observed in mice expressing neuroligin 1}

We used a gain-of-function approach to examine whether manipulations of the levels of NLs in vivo influence synapse function leading to altered behavior. For these experiments, transgenic animals overexpressing NL1 (TgNL1) and NL2 (TgNL2) were generated (Fig. 1 $A, B$ ). The transgenes were under the control of Thyl promoter, which allows for expression in various brain regions at early stages of development. To facilitate detection of the transgene, influenza hemagglutinin (HA) tags were inserted (between amino acids 45 and 46) immediately after the NL1 signal sequence. To compare transgene expression and localization with wild-type NL2, a specific antibody was generated. This antibody was tested for specificity on lysates from Cos cells expressing HA-NL1, HA-NL2, or HA-NL3 (Fig. 1C). In addition, the antibody was tested in cultured hippocampal neurons for predominant colocalization with vesicular GABA transporter (VGAT) (supplemental Fig. $1 B$, available at www.jneurosci.org as supplemental material) and in tissue from TgNL2 mice for correspondence with HA-tagged transgene (supplemental Fig. $1 C$, available at www.jneurosci.org as supplemental material).

The generated TgNL1 and TgNL2 strains were viable; however, TgNL2 mice exhibited a striking and distinct phenotype. TgNL2 mice with moderate to high levels of expression (Fig. $1 D, F)$ showed reduced lifespan and capacity to produce viable offspring. One additional feature of the TgNL2 phenotype is limb clasping (Fig. $1 E$ ), a defect associated with mouse models of neurological disorders such as Rett syndrome (Gemelli et al., 2006). This feature was not observed at comparable levels in TgNL1 strains with similar transgene expression (Fig. 1B) (1.25- to 1.71fold TgNL2.6 HA expression).

\section{Behavioral test battery demonstrates a consistent, dose- dependent phenotype in mice expressing neuroligin 2 not observed in mice expressing neuroligin 1}

The preliminary behavioral screen was conducted on all founders and strains generated based on the modified SHIRPA screen from the EMPReSS (Brown et al., 2005, 2006). The preliminary screen revealed striking and consistent abnormalities among all TgNL2 strains generated that increased with level of expression (Table 1, - indicates no difference from wild type). Animals with twofold or greater expression of NL2 (determined by Western blot; TgNL2.1, TgNL2.4, and TgNL2.5) showed the most striking phenotype with frequent limb clasping and death by 24 postnatal weeks, and these strains also failed to produce viable offspring. The primary strain has moderate expression level and phenotype (TgNL2.6; 1.6-fold wild-type NL2 expression) and has reproduced successfully over nine generations; thus, most of the analysis performed was on this strain. Whenever possible, results obtained from a higher expressing strain (TgNL2.7; 1.9-fold wildtype NL2) are included for comparison.

In general, TgNL2 mice are characterized by a reduction in body weight (supplemental Fig. $2 B-D$, available at www. jneurosci.org as supplemental material), limb clasping (Fig. $1 E, F)$, Straub tail, transient episodes of kyphosis (supplemental Fig. 2A, available at www.jneurosci.org as supplemental material), as well as enhanced basal activity and enhanced startle response to a $90 \mathrm{~dB}$ click (Table 1). However, no overt changes were observed in autonomic indicators such as palpebral closure and piloerection (Table 1, Autonomic). In addition, somatosensory, visual, auditory, and olfactory systems were also found to be intact in TgNL2 mice using a battery of multiple tests (Table 1, Sensory). Basic muscle and motor assessments in TgNL2 mice revealed normal body and limb tone, and intact righting reflex (Table 1, Muscle and motor). The drastic phenotypic changes observed on relatively small alterations in transgene expression (1.6- to 2-fold endogenous NL2), combined with the dose-dependent change in the severity of phenotype, indicates that the effects seen are not because of excessive protein overexpression in vivo. Moreover, the lack of these abnormalities in TgNL1 further suggests that the observed changes in TgNL2 mice have resulted from alterations attributable to specific manipulation of NL2 levels in vivo. 
Table 1. Summary of the preliminary screen conducted on all strains

\begin{tabular}{|c|c|c|c|c|c|c|c|c|c|}
\hline & WT & TgNL1.6 & TgNL1.7 & $\operatorname{TgNL2.6}$ & TgNL2.7 & TgNL2.1 & $\operatorname{TgNL2.3}$ & $\operatorname{TgNL2.4}$ & $\operatorname{TgNL} 2.5$ \\
\hline \multicolumn{10}{|l|}{ General } \\
\hline Viability & - & - & - & - & 1 early adult & 1 early adult & 1 early adult & 1 early adult & 1 early adult \\
\hline Offspring viability & - & 1 incr \# dead & 1 incr \# dead & 1 incr \# dead & 2 high \# dead & 3 none viable & 3 none viable & 3 none viable & 3 none viable \\
\hline \multicolumn{10}{|l|}{ Autonomic } \\
\hline Palpebral closure & - & - & - & - & - & - & - & - & - \\
\hline Piloerection & - & - & - & - & - & - & - & - & - \\
\hline Tail position & - & - & - & 2 Straub tail & 2 Straub tail & 2 Straub tail & 2 Straub tail & 2 Straub tail & 2 Straub tail \\
\hline \multicolumn{10}{|l|}{ Sensory } \\
\hline \multicolumn{10}{|l|}{ Somatosensory } \\
\hline Transfer arousal & - & - & - & - & - & - & - & - & - \\
\hline Touch escape & - & - & - & - & - & - & - & - & - \\
\hline \multicolumn{10}{|l|}{ Visual } \\
\hline Corneal reflex & - & - & - & - & - & - & - & - & - \\
\hline Visual placing & - & - & - & - & - & - & - & - & - \\
\hline \multicolumn{10}{|l|}{ Auditory } \\
\hline Pinna reflex & - & - & - & - & - & - & - & - & - \\
\hline Acoustic startle (90 dB click) & - & - & - & 1 jump $<1 \mathrm{~cm}$ & 1 jump $<1 \mathrm{~cm}$ & 1 jump $<1 \mathrm{~cm}$ & 2 jump $>1 \mathrm{~cm}$ & 2 jump $>1 \mathrm{~cm}$ & 2 jump $>1 \mathrm{~cm}$ \\
\hline \multicolumn{10}{|l|}{ Olfactory } \\
\hline Buried food retrieval & - & - & - & - & - & - & - & - & - \\
\hline \multicolumn{10}{|l|}{ Muscle and motor } \\
\hline Body position & - & - & - & 1 rare kyphosis & 2 kyphosis & 2 kyphosis & 2 kyphosis & 2 kyphosis & 2 kyphosis \\
\hline Body tone and limb tone & - & - & - & - & - & - & - & - & - \\
\hline Righting reflex & - & - & - & - & - & - & - & - & - \\
\hline Basal activity & - & - & - & 2 rear/leap & 2 rear/leap & 2 rear/leap & 1 rapid darting & 1 rapid darting & 1 rapid darting \\
\hline Open field speed/distance & - & - & - & - & - & - & - & - & - \\
\hline
\end{tabular}

Table shows scores for WT, TgNL1, and TgNL2 strains; transgenic strains are arranged in order of increasing expression of transgene. - indicates normal or no impairment; in the case of impairment, increasing values indicate increased impairment, and a brief description is provided. For detailed description of methods, observations, and scoring, see supplemental Methods (available at www.jneurosci.org as supplemental material).

Expressed neuroligin 2 is distributed throughout the neuroaxis in neuronal cells and is predominantly localized to inhibitory synaptic contacts

To assess exogenous NL2 expression in detail, multiple approaches were used. Both immunohistochemistry and in situ hybridization revealed broad distribution of the HA-NL2 transcript and protein in TgNL2.6 (Fig. 2A-C). Despite varied levels of expression between transgenic strains as revealed by Western blotting, the pattern of HA-NL2 staining was consistent. HANL2 was expressed throughout the neuroaxis, with high levels in the cortex and limbic structures, such as amygdala and hippocampus (Fig. 2B,C). Staining of cortical cultures from TgNL2.6 confirmed that HA-positive $\left(\mathrm{HA}^{+}\right)$labeling was exclusive to neuronal cells $\left[4^{\prime}, 6^{\prime}\right.$-diamidino-2-phenylindole-positive, MAP-2-negative (MAP-2 ${ }^{-}$), $\left.\mathrm{HA}^{-}\right]$and could be detected in large numbers of neurons (supplemental Fig. $1 D$, available at www.jneurosci.org as supplemental material). Similar to wildtype NL2, HA-NL2 predominantly colocalized with inhibitory (gephyrin) and to a lesser extent with excitatory (PSD-95) postsynaptic markers, demonstrating that exogenous HA-NL2 is not mislocalized (Fig. 2D,E).

\section{Enhancement of markers of presynaptic terminals in mice expressing neuroligin 2}

Given the implication of NLs in modulation of the E/I ratio, we analyzed changes in the content of excitatory and inhibitory synapses in TgNL2 mice. Quantitative Western blotting analysis of forebrain lysates revealed significant changes in the amounts of VGAT, vesicular glutamate transporter (VGluT) and syntaxin but not in the expression of PSD-95 and gephyrin (Fig. 3A,B), suggesting a change in the content of presynaptic but not postsynaptic elements of both excitatory and inhibitory synapses. Assessments of other NL family members revealed no change in NL1 but a significant decrease in NL3 expression levels in TgNL2 brain lysates (Fig. $3 A, B$ ). Interestingly, TgNL1 mice show opposing alterations in related protein expression levels, with a significant increase in both NL3 and PSD-95 (data not shown).

Immunostaining of frontal cortex sections from P28 TgNL2 mice showed altered VGAT and VGluT staining intensity (Fig. $3 C, D)$. Consistent with the enrichment of NL2 at the majority of GABAergic synapses, more robust increases were seen in the average integrated intensity (VGAT, 1.7-fold; VGLuT, 1.3-fold) of inhibitory contacts in the frontal cortex. The ratio of VGluT to VGAT staining intensity in the frontal cortex was significantly decreased in TgNL2 when compared with wild-type littermates (Fig. 3E) revealing a bias toward increased inhibition during in vivo expression of NL2.

EM analysis reveals changes in synapse morphology and an increase in inhibitory contacts in frontal cortex of mice expressing neuroligin 2

Ultrastructural EM analysis of medial prefrontal cortex (MPFC) of TgNL2.6 and TgNL2.7 brain demonstrated changes in the morphology of synaptic components (Fig. 4C) and synapse density. Marked increases were observed in the number of vesicles in the reserve pool (Fig. $4 A, D$ ), as well as the area of symmetric (type II, typically inhibitory) presynaptic compartments (Fig. $4 A, E$ ) and contact length of symmetric synapses (Fig. $4 A, F$ ) in TgNL2 mice. In addition, a small but significant change was observed in asymmetric (type I, typically excitatory) presynaptic compartment area (Fig. 4B,E). No change was observed in the average length of postsynaptic densities in TgNL2 mice (Fig. $4 B, D)$.

Using unbiased stereological analysis, a modest increase in the total density of synapses, as well as the density of symmetrical synapses was observed in both TgNL2.6 and TgNL2.7 (Fig. $4 G, H)$. No changes were seen in the total number of neurons in the frontal cortex (supplemental Fig. $3 A, B$, available at www. 
A $\mathrm{TgNL} 2.6-\mathrm{HA}$

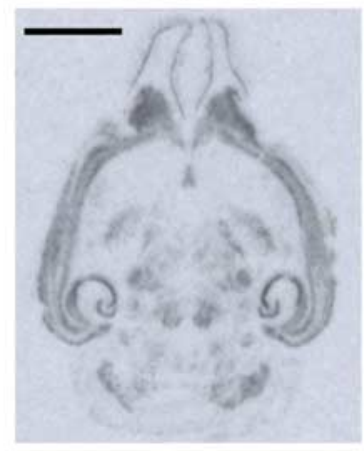

B
TgNL2.6-NL2

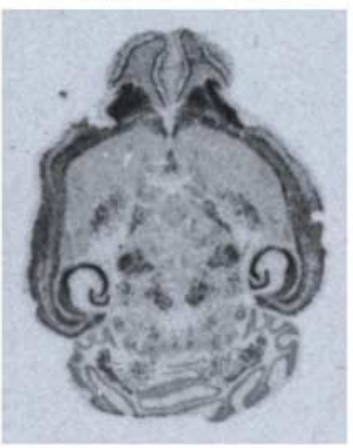

Wt anti-HA
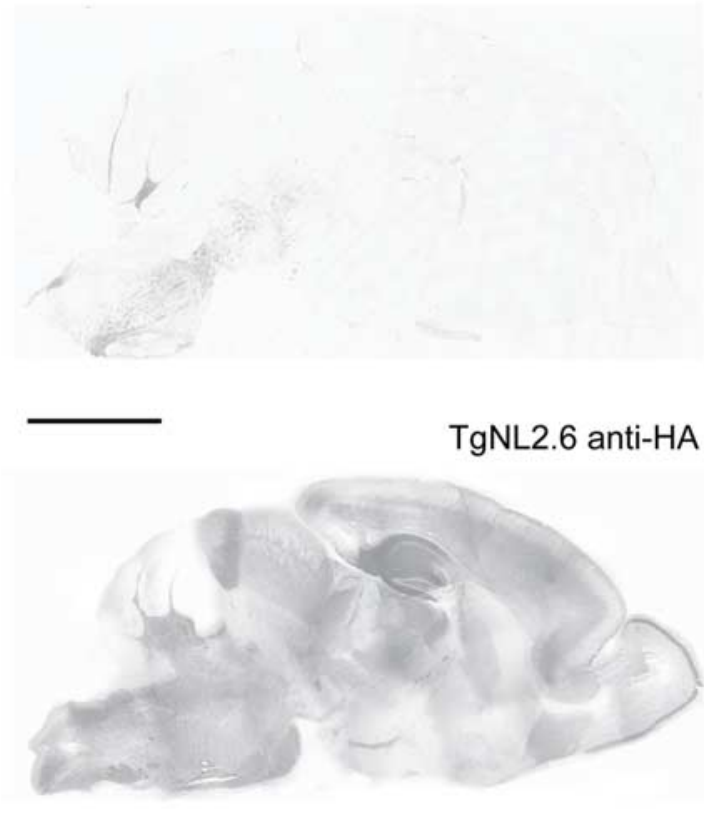

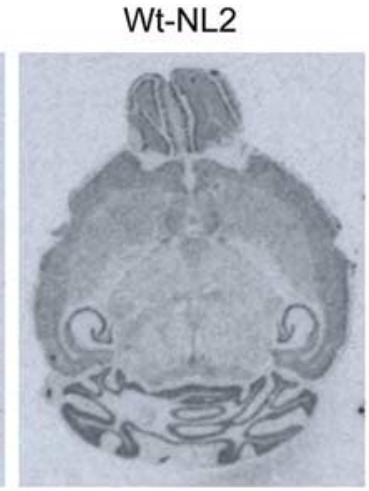

\section{C}
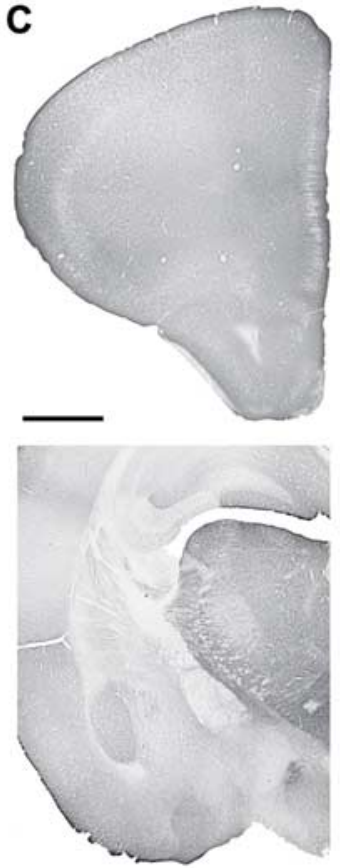

D

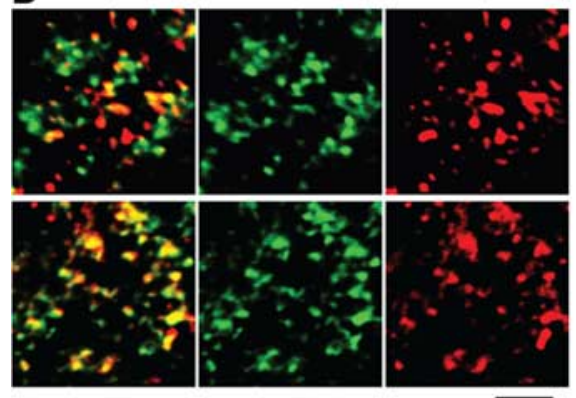

E

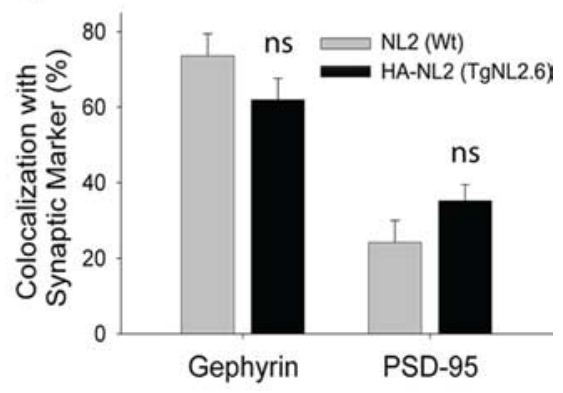

Figure 2. Neuroligin 2 transgene distribution and localization. $A$, In situ hybridization analysis of HA-containing transcript in TgNL2.6 (left) and of NL2-containing RNA in TgNL2.6 (middle) and WT (right). Scale bar, 3 mm. B, DAB immunohistochemistry for HA in sagittal sections from WT and TgNL2.6. Scale bar, $3 \mathrm{~mm}$. C, HA DAB immunostaining in coronal sections through the frontal cortex (bregma, 2.71-2.22 mm) and hippocampus/amygdala (bregma, -1.28 to $-1.64 \mathrm{~mm}$ ) of TgNL2.6 brain. Scale bar, $1 \mathrm{~mm}$. D, Confocal analysis of colocalization of HA-NL2 (green) and excitatory (PSD-95, red, top panel) and inhibitory (gephyrin, red, bottom panel) synaptic markers in the frontal cortex. Scale bar, $2 \mu \mathrm{m}$. $\boldsymbol{E}$, Quantification of excitatory (PSD-95; WT, $24.21 \pm$ 5.50\%; TgNL2.6, 35.20 $\pm 3.51 \% ; t$ test, $p=0.181$ ) and inhibitory (gephyrin; WT, $73.60 \pm 5.86 \% ; \operatorname{TgNL2.6,61.91~} \pm 5.38 \% ; t$ test, $p=0.176$ ) marker colocalization with endogenous NL2 in wild-type frontal cortex compared with HA-NL2 in TgNL2.6 frontal cortex. Data shown are means \pm SEMs; WT and TgNL2.6, $n=9$. ns, Not significant.

jneurosci.org as supplemental material). By dividing the density of asymmetric synapses by the density of symmetric synapses, we can estimate a shift in the E/I ratio toward inhibition in TgNL2 frontal cortex compared with littermate controls (Fig. 4I), sup- porting the finding of a decreased ratio of VGluT to VGAT immunostaining in TgNL2.6 frontal cortex.

Together, these results suggest an effect of NL2 in vivo on the modulation of synapse morphology with primary effects on presynaptic terminals and, in particular, symmetric synapses. The small effects of NL2 on asymmetric presynaptic terminals are not surprising because endogenous NL2 can be found at $\sim 20-30 \%$ of excitatory synapses (Fig. 2E). Given the effects on symmetrical synapse density, it is also possible that changes observed in the morphology of asymmetrical terminals are a means of compensation. The greater degree of change observed in inhibitory versus excitatory synapses suggest that enhanced expression of NL2 results in an overall reduction in the $\mathrm{E} / \mathrm{I}$ ratio, revealing that a small increase in NL2 expression results in alterations in synaptic balance in frontal cortex.

\section{Altered synaptic transmission in prefrontal cortex of mice expressing neuroligin 2}

Whole-cell patch-clamp recordings were performed in pyramidal neurons in layer II/III of wild-type and TgNL2.6 prefrontal cortex. Recording of spontaneous activity revealed that the frequency of miniature IPSCs (mIPSCs) is increased in TgNL2 mice compared with those in wild-type mice (Fig. 5A,B). However, the mIPSC amplitude was not altered in the prefrontal cortex of TgNL2 mice (Fig. $5 A, B$ ). In contrast to inhibitory currents, neither frequency (Fig. $5 C, D$ ) nor amplitude (Fig. $5 C, D$ ) of mEPSCs in TgNL2 mice were found to be significantly different from those in the prefrontal cortex of wild-type mice (Fig. $5 A-C$ ). These results are consistent with the EM data suggesting a primary effect of NL2 expression on modulating inhibitory synapse function.

\section{Altered neuroligin 2 expression leads to spontaneous stereotypies and anxiety behavior}

To assess the behavior of TgNL2 mice in more detail, we next observed mice in the open field paradigm. When in the open field, TgNL2.6 mice display spontaneous jumping stereotypies in the corners of the arena (Fig. 6A) (supplemental Video 1, available at www.jneurosci.org as supplemental material). Stereotyped patterns of behavior can be induced in animals by treatment with amphetamines and cocaine or by deprivation (Powell et al., 1999; Würbel, 2001) and have also been observed in mouse models of mental retardation such as the Down syndrome model Ts65Dn (Turner et al., 2001). Stereotyped jumping behav- 
A

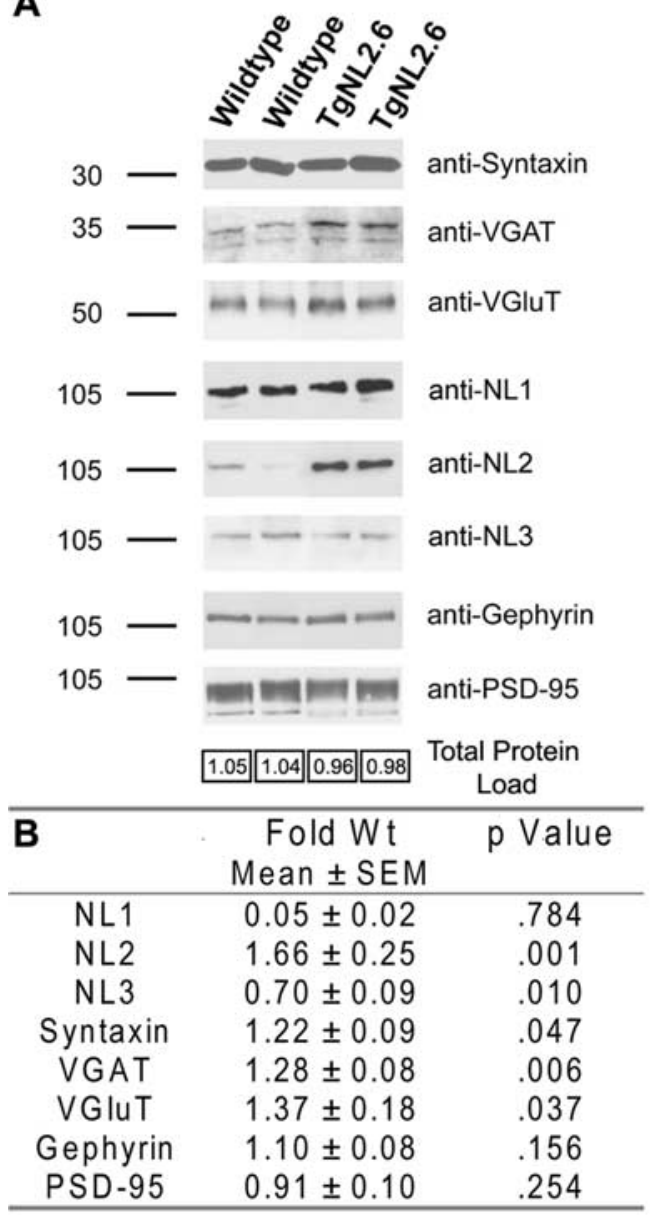

C
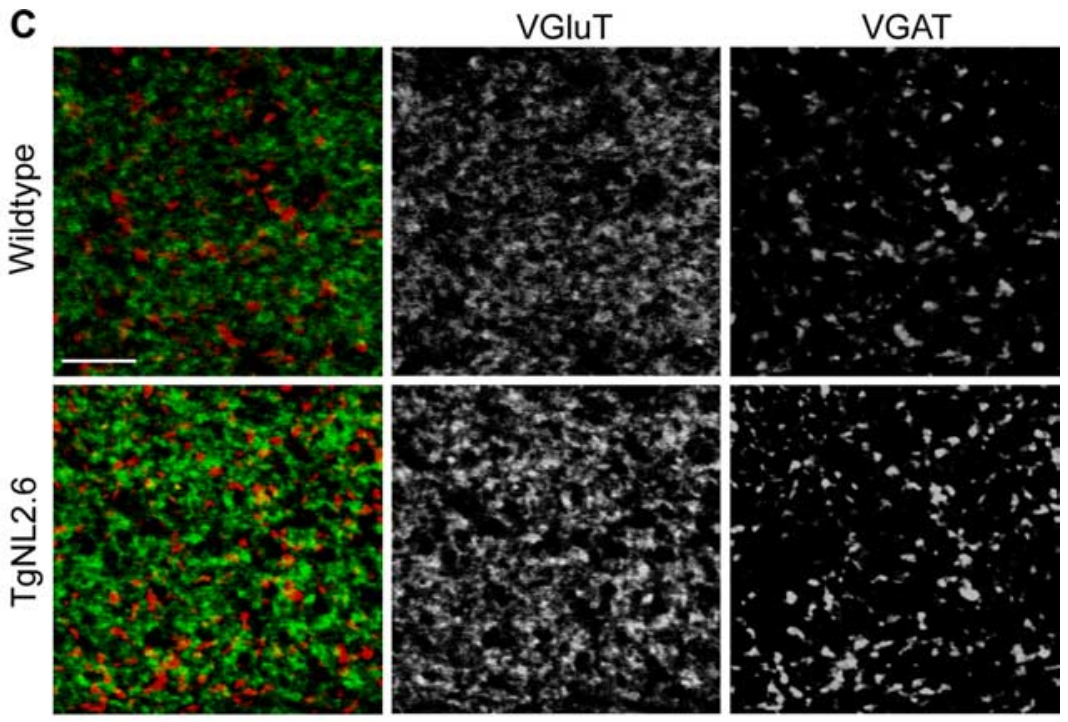

D

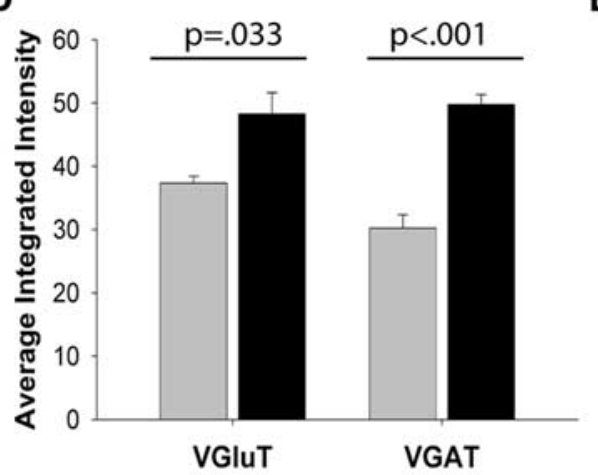

E

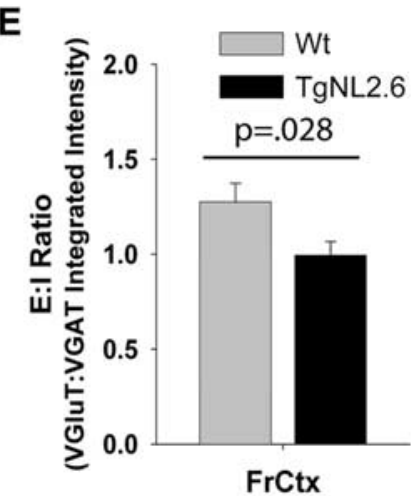

Figure 3. Western blotting and immunohistochemical assessment of synaptic proteins in mice expressing neuroligin 2. $\boldsymbol{A}$, Representative blots for synaptic proteins assayed in wild-type and TgNL2.6 mice. B, Quantification of Western blot normalized to total protein load from Coomassie-stained gels and compared with WT expression level. $\boldsymbol{C}$, Confocal microscopy of VGluT (middle, green) and VGAT (right, red) staining in wild-type (top) and TgNL2.6 (bottom) MPFC. Scale bar, $5 \mu \mathrm{m}$. D, Quantification of the average integrated intensity of VGluT (WT, 37.37 $\pm 1.00 ;$ TgNL2.6, $48.29 \pm 3.29 ; t$ test, $p=0.033$ ) and VGAT (WT, 30.26 $\pm 2.02 ;$ TgNL2.6, $49.76 \pm 1.53 ; t$ test, $p<0.001$ ) puncta in MPFC. $E$, The ratio of excitation to inhibition as expressed by the ratio of VGluT intensity/VGAT intensity (WT, $1.28 \pm 0.09 ; \mathrm{TgNL2} .6,1.00 \pm 0.07 ; t$ test, $p=0.028$ ). Data shown are means \pm SEMs; WT and TgNL2.6, $n=9$.

ior is typically preceded by rearing against the arena wall and is characterized by repeated jumping vertically on hindlegs and balancing on a rigid tail (supplemental Video 1, available at www. jneurosci.org as supplemental material) (Würbel and Stauffacher, 1996; Garner and Mason, 2002). The jumping stereotypy was also observed when TgNL2.6 mice were in the home cage (in the presence of social and environmental enrichment); however, repetitive jumping was never observed in wild-type littermates $(n=50)$. Not all TgNL2.6 mice showed stereotypies during open field observation, and it was found that $44 \%$ of TgNL2.6 males $(n=50)$ show more than one episode of stereotypy during a 5 min open field exploration (Fig. 6B). TgNL2.6 mice showing stereotypies typically display high levels of this behavior, with an average of $\sim 10$ episodes over the 5 min period (Fig. 6 B). TgNL2.6 mice displaying more than one episode of jumping stereotypy during a 5 min prescreening session in the open field were excluded from behavioral assessments of anxiety and social behavior to avoid possible confounds of this behavior (for details, see supplemental Methods, available at www.jneurosci.org as supplemental material) (Garner, 2005). Other types of repeated behavior patterns were also monitored in the open field, such as digging and grooming, but the incidence of these types of behaviors was not significantly different from wild-type littermates
(Fig. 6A). It has been shown that stereotyped patterns of behavior that result from drug sensitization can be blocked by antagonists or induced by agonists of the GABAergic system (Karler et al., 1995); thus, it is possible that this behavior arises as a result of the alterations in GABAergic transmission observed in the frontal cortex (Karler et al., 1997) of TgNL2 mice.

During the open field test, we also observed indications of anxiety behavior in TgNL2 mice. Both TgNL2.6 and TgNL2.7 mice show thigmotaxis (Fig. 6C), as demonstrated by a decrease in both average (supplemental Fig. 4A, available at www. jneurosci.org as supplemental material) and cumulative (Fig. $6 D$ ) distance from the arena border compared with wild-type mice. TgNL2 mice also show increased rearing frequency, which is further indicative of anxiety (supplemental Fig. $4 B$, available at www.jneurosci.org as supplemental material). However, no changes were observed in average speed traveled while exploring the open field (data not shown; wild type, $4.75 \mathrm{~cm} / \mathrm{s}$; TgNL2.6, $6.07 \mathrm{~cm} / \mathrm{s}$; TgNL2.7, $6.18 \mathrm{~cm} / \mathrm{s} ; p=0.169)$ or total distance traveled in the open field (supplemental Fig. $4 C$, available at www. jneurosci.org as supplemental material), demonstrating that TgNL2 animals do not have motor impairments or lack exploratory motivation.

To confirm that the thigmotaxis observed in the open field 

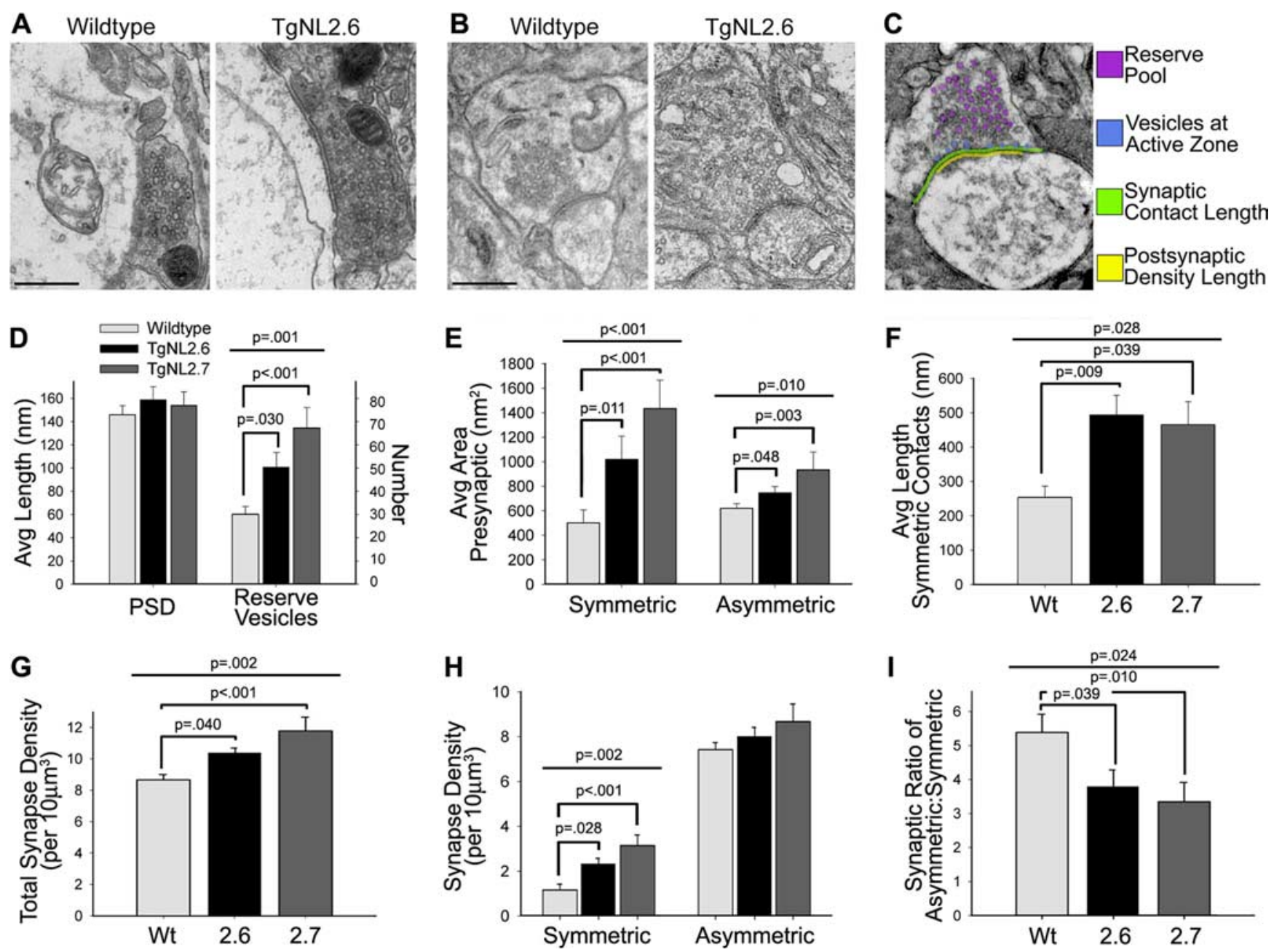

Figure 4. Synaptic abnormalities in mice expressing neuroligin 2.A, $\boldsymbol{B}$, Representative electron micrographs of symmetric $(\boldsymbol{A})$ and asymmetric $(\boldsymbol{B})$ synapses in wild-type and TgNL2.6 MPFC. Scale bars, $500 \mathrm{~nm}$. C, Synaptic elements quantified are highlighted. D, E, Quantification of the length of the postsynaptic density (WT, $146.05 \pm 7.78 ;$ TgNL2.6, 180.00 $\pm 15.14 ;$ TgNL2.7, 139.96 \pm 10.35 ) and number of vesicles in the reserve pool (WT, $30.93 \pm 3.24 ; \mathrm{TgNL2} .6,51.87 \pm 6.37 ; \mathrm{TgNL2} .7,69.27 \pm 8.87 ;$ ANOVA, $F_{(2,42)}=8.52, p=0.001 ;$ post hoc tests, $p=0.030$ WT vs TgNL2.6, $p<0.001$ WT vs TgNL2.7) and presynaptic compartment area (symmetric: WT, $501.54 \pm 71.79 ;$ TgNL2.6, $1020.11 \pm 131.01 ; \operatorname{TgNL2.7,} 1436.04 \pm 157.72 ;$ ANOVA, $F_{(2,65)}=8.57, p<0.001 ; p 0 s t$

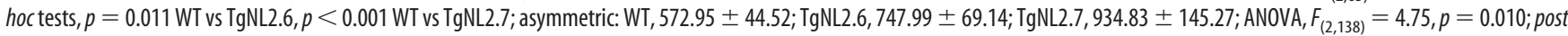
hoc tests, $p=0.048$ WT vs TgNL2.6, $p=0.003$ WT vs TgNL2.7) in wild-type, TgNL2.6, and TgNL2.7 MPFC. $\boldsymbol{F}$, Analysis of the length of contact between symmetric presynaptic and postsynaptic compartments (WT, 254.34 $\pm 32.46 ;$ TgNL2.6, 493.87 $\pm 57.00 ;$ TgNL2.7, 465.59 $\pm 66.36 ;$ ANOVA, $F_{(2,31)}=4.03, p=0.028 ;$ post hoc tests, $p=0.009$ WT vs TgNL2.6, $p=0.039$ WT vs TgNL2.7) in wild-type, TgNL2.6, and TgNL2.7 symmetric synapses. $\boldsymbol{G}, \boldsymbol{H}$, Number of total (WT, $8.69 \pm 0.34 ;$ TgNL2.6, $10.42 \pm 0.34 ;$ TgNL2.7, $11.81 \pm 0.88 ;$ ANOVA, $F_{(2,45)}=7.28, p=0.002 ;$ post hoc tests, $p=0.040$ WT vs TgNL2.6, $p<0.001$ WT vs TgNL2.7), symmetric (WT, $7.30 \pm 0.35 ;$ TgNL2.6, $7.99 \pm 0.44 ; \operatorname{TgNL2.7,8.69} \pm 0.78 ;$ ANOVA, $\left.F_{(2,45)}=1.58, p=0.219\right)$, and asymmetric (WT, $1.16 \pm$ $0.28 ;$ TgNL2.6, $2.32 \pm 0.28 ;$ TgNL2.7, $3.13 \pm 0.49 ;$ ANOVA, $F_{(2,45)}=7.55, p=0.002 ; p o s t$ hoc tests, $p=0.028$ WT vs TgNL2.6, $p<0.001$ WT vs TgNL2.7) synapses per $10 \mu \mathrm{m}^{3}$ field of MPFC neuropil. $I$, The ratio of excitation to inhibition as expressed by the ratio of asymmetric: symmetric synapses (WT, $5.89 \pm 0.60 ; \operatorname{TgNL2} .6,4.14 \pm 0.53 ; \mathrm{TgNL2} .7,3.67 \pm 0.60 ;$ ANOVA, $F_{(2,45)}=4.09$, $p=0.024 ;$ post hoc tests, $p=0.039$ WT vs TgNL2.6, $p=0.010$ WT vs TgNL2.7). Data shown are means \pm SEMs. Synapse density: WT and TgNL2.6, $n=4$ mice, $n=16$ fields; TgNL2.7, $n=3$ mice, $n=16$ fields.

was indicative of anxiety, we also compared the moderate expressing TgNL2.6 strain with wild-type littermates in the light-dark exploration test. Observation of TgNL2.6 mice in the light/dark test revealed an increase in the percentage of time spent in the dark compartment compared with wild-type littermates (Fig. 6E). However, no change was observed in the number of transitions between the light and dark compartments (supplemental Fig. 4D, available at www.jneurosci.org as supplemental material), which is an additional measure of anxiety-like behavior in the light/dark test. It has been reported that the most consistent measure of anxiety using the light/dark test is the percentage of time spent in each compartment, and transitions have been suggested to be influenced by activity or exploration (Belzung et al., 1987; Hascoët and Bourin, 1998; Bourin and Hascoët, 2003). Although it is un- clear why TgNL2 mice display an anxiety-like phenotype on only one of the two measures for the light/dark task, it is possible that the high level of basal activity observed in TgNL2 may obscure detection of differences in the number of transitions.

To further confirm an anxiety-like phenotype, mice were also tested in the elevated plus maze. TgNL2.6 mice demonstrated a reduction in the percentage of time spent in the open arms (Fig. $6 F$ ), as well as in the percentage of entries made into open arms (Fig. $6 \mathrm{~F}$ ) of the elevated plus maze compared with wild-type littermate controls. No difference was observed in the total number of entries (supplemental Fig. $4 E$, available at www.jneurosci. org as supplemental material), supporting the idea that TgNL2.6 performance on this task is not limited by motor impairments or lack of exploratory motivation. Overall, these three assessments 


\section{A mIPSCs}

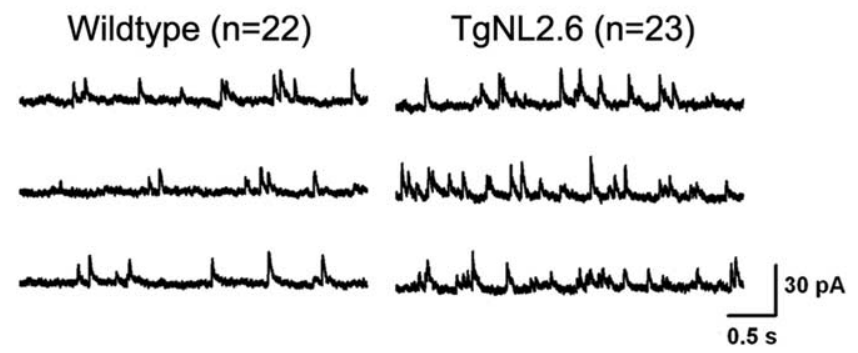

$B$
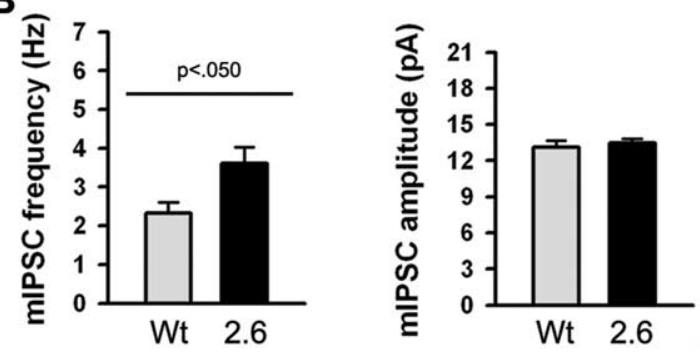

C

mEPSCs

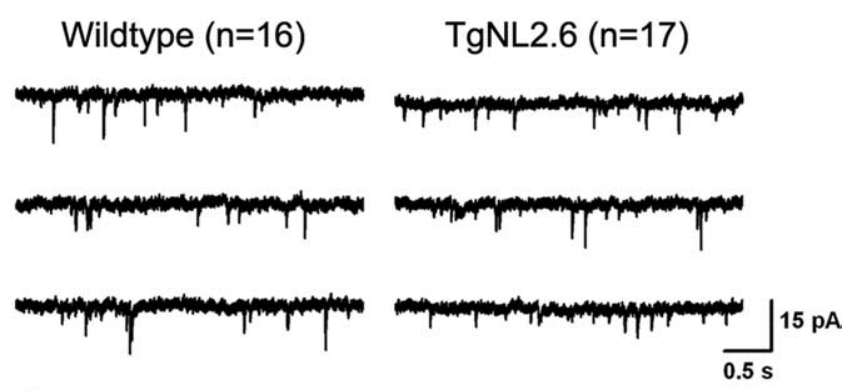

D
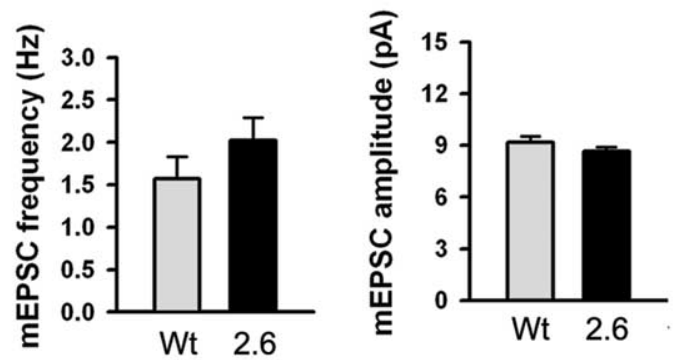

Figure 5. Increased inhibitory synaptic transmission in pyramidal neurons of prefrontal cortex in mice expressing neuroligin 2. $A$, Representative traces showing the mIPSCs in wild-type and TgNL2.6 mice. TTX (1 $\mu \mathrm{m})$, CNQX (20 $\mu \mathrm{m})$, and AP-5 (50 $\mu \mathrm{m})$ was added in the ACSF during mIPSC recordings. $\boldsymbol{B}$, Statistical results showing the significant increase of mIPSC frequency (left; WT, $2.3 \pm 0.3, n=22 ; \operatorname{TgNL2} .6,3.6 \pm 0.4, n=23 ; t$ test, $p<0.050$ ) but not amplitude (right; WT, $13.1 \pm 0.5, n=22 ; \operatorname{TgNL2} .6,13.5 \pm 0.3, n=23 ; t$ test, $p=0.55$ ) in TgNL2.6 mice compared with wild-type mice. $C$, Typical traces showing the mEPSCs recorded in wild-type (left) and TgNL2.6 (right) mice. TTX (1 $\mu \mathrm{m})$, picrotoxin (100 $\mu \mathrm{m})$, and AP-5 (50 $\mu \mathrm{m})$ was added in the ACSF during mEPSC recordings. $D$, Statistical results showing normal mEPSC frequency (left; WT, $1.6 \pm 0.3, n=16 ; \operatorname{TgNL2} .6,2.0 \pm 0.3, n=17 ; t$ test, $p=0.24$ ) or amplitude (right; WT, 9.2 $\pm 0.3, n=16 ; \operatorname{TgNL2} .6,8.7 \pm 0.2, n=17 ; t$ test, $p=0.21$ ) in TgNL2.6 mice compared with wild-type mice. Data shown are means \pm SEMs.

indicate an increase in anxiety-like behavior in mice expressing NL2 compared with their littermate controls.

Mice expressing neuroligin 2 display abnormalities in social behavior

To assess reciprocal social interactions of TgNL2 mice, male mice were placed into a neutral home cage with a novel juvenile target male of a different strain (FVB). The two animals were allowed to freely interact over the course of $5 \mathrm{~min}$, and the number and duration of interactions were manually assessed from video recordings. A striking reduction in the total time of interaction with the novel target mouse was observed in TgNL2 mice when compared with wild-type littermates (Fig. 7A). Although TgNL2.6 mice did not show a difference in the total number of interactions with novel juveniles (Fig. $7 C$ ), the average duration of individual interactions was significantly reduced (Fig. $7 B$ ). The lack of change in the total number of interactions is likely to result from increased initiation of interactions by the freely moving target mouse (Fig. 7D).

To further assess social behavior and rule out a general defect in their interaction with novel stimuli, we assessed TgNL2.6 mice in a counterbalanced social approach apparatus based on the task developed by the laboratory of Dr. J. N. Crawley (Fig. 7E) (Moy et al., 2004; Nadler et al., 2004). In this three-chambered apparatus, wild-type mice show a strong preference for the chamber containing the novel mouse over either the center or counterbalanced novel object chamber. This effect can be seen in the total amount of time spent in the chamber with the novel mouse (Fig. $7 F$ ). In contrast, TgNL2.6 mice do not show this preference, with no significant difference between the time spent in the novel mouse chamber compared with the novel object chamber. In addition, wild-type mice also display preference for the novel mouse chamber by the number of investigative rears made in this chamber (Fig. 7G), indicating a high level of exploration of the novel mouse. In contrast, TgNL2.6 mice do not demonstrate preference for the novel mouse chamber over the novel object chamber in terms of high levels of rearing. This result of reduced social approach in the three-chambered apparatus, in conjunction with reduced reciprocal social interactions, demonstrates that TgNL2 animals are impaired in the natural preference for social interaction seen in wild-type mice.

\section{Chronic EEG recording in freely moving neuroligin 2} transgenic mice reveals bilateral spike-wave discharges Synapse anomalies and behavioral observations prompted assessment of spike wave patterns via frontoparietal EEG recordings in TgNL2 mice. Neck electromyogram (EMG) was recorded to establish whether spiking occurred during different sleep and wake states. Eight of the 10 TgNL2 animals studied demonstrated brief bilateral bursting activity characterized by spike-wave discharge of $\sim 6-8 \mathrm{~Hz}$ (Fig. $8 A, B$ ). The spike-wave episodes were brief, did not always occur with specific behaviors, and could be identified in both awake and sleep states (Fig. 8C). The results indicate that even a mild increase in the expression of NL2 results in spiking activity. Despite the detection of spiking activity by EEG, TgNL2.6 mice did not exhibit any overt visible signs of seizure. The spiking activity observed by frontoparietal EEG may be attributable to desynchronized cortical activity patterns or as a result of spreading excitation from other brain regions.

\section{Discussion}

Our analysis reveals that manipulation of NL2 expression results in altered synapse morphology and function. Previous studies indicate that altered levels of individual NLs at particular synaptic sites modulate synapse maturation and neuronal excitability (Levinson and El-Husseini, 2005). Consistent with these findings, EM and electrophysiological analyses of frontal cortical areas in transgenic NL2 mice reveal an increase in the size and number of inhibitory synaptic contacts and enhanced frequency of presynaptic currents. Thus, the net result is potentiation of 


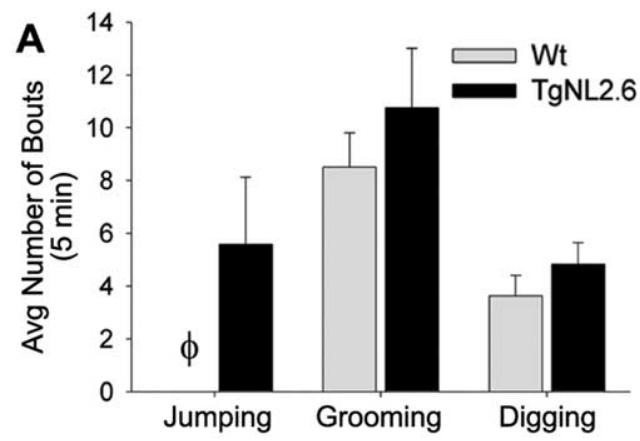

B

\begin{tabular}{|l|c|c|}
\hline & Wildtype & TgNL2.6 \\
\hline $\begin{array}{l}\text { \% with Jumping } \\
\text { Stereotypy } \\
(n=50)\end{array}$ & 0 & 44 \\
\hline $\begin{array}{l}\text { Avg Number of } \\
\text { Bouts in 5 min } \\
(n=22)\end{array}$ & n/a & $9.57 \pm 3.72$ \\
\hline
\end{tabular}

C

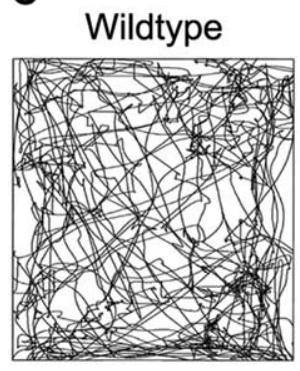

$\operatorname{TgNL2.6}$

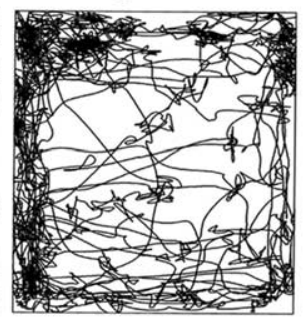

D
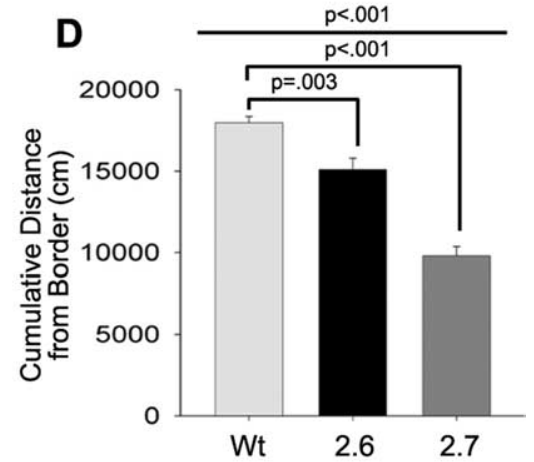

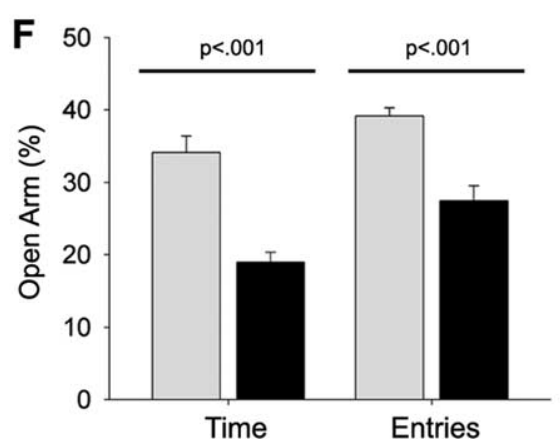

Figure 6. Neuroligin 2-expressing mice display spontaneous jumping stereotypies and anxiety behavior. $A$, Graph plotting the incidence of stereotyped jumping (WT, 0 ; TgNL2.6, $5.58 \pm 2.53$ ), digging (WT, $8.50 \pm 1.31 ; \operatorname{TgNL2} 2.6,10.75 \pm 2.63 ; t$ test, $p=$ 0.461 ), and grooming (WT, 3.63 $\pm 0.78 ; \mathrm{TgNL} 2.6,4.83 \pm 0.81 ; t$ test, $p=0.318$ ) behaviors in the open field (WT, $n=7$; TgNL2.6, $n=8$ ). $\phi$ Signifies that wild-type animals did not demonstrate this behavior, under any of the conditions examined. $\boldsymbol{B}$, Table showing the percentage of wild-type (0\%) and TgNL2.6 (44\%) mice showing stereotypies in a larger population $(n=50)$ and, of these mice, the average number of stereotypies shown in a 5 min open field session. C, Representative paths of wild-type (left) and TgNL2 (right) mice in the open field arena. $\boldsymbol{D}$, Assessment of the cumulative distance from the arena border (WT, 17,965.74 \pm 379.79; TgNL2.6, 15,088.26 $\pm 709.59 ;$ TgNL2.7, 9784.31 $\pm 570.32 ;$ ANOVA, $F_{(2,17)}=30.51, p<0.001 ;$ posthoctests, $p=0.001$ WT vs TgNL2.6, $p<0.001$ WT vs TgNL2.7) in the open field task. E, Percentage of time spent in the dark chamber (WT, $64.90 \pm$ 4.21; TgNL2.6, $81.58 \pm 3.55 ; t$ test, $p=0.022$ ) by wild-type and TgNL2.6 mice during the light/dark exploration test. $\boldsymbol{F}$, Assessment of the percentage of open arm time (WT, 34.17 $\pm 2.92 ;$ TgNL2.6, $18.94 \pm 1.45 ; t$ test, $p<0.001$ ) and open arm entries (WT, 38.86 $\pm 1.39 ;$ TgNL2.6, $27.46 \pm 2.15 ; t$ test, $p<0.001$ ) by wild-type and TgNL2.6 mice in the elevated plus maze. Data shown are means \pm SEMs. Open field: wild-type, $n=7 ; \operatorname{TgNL2.6,~} n=8 ; \operatorname{TgNL2.7,} n=2$. Light/dark exploration test: wild-type and TgNL2.6, $n=8$. Elevated plus maze: wild-type and TgNL2.6, $n=8$.

inhibitory responses in the frontal cortex, revealing a shift in the balance toward inhibition.

The observed phenotypic changes were attributable to small alteration in NL2 expression (1.6- to 2-fold above endogenous levels of NL2). These findings indicate that the effects seen are not attributable to excessive protein overexpression in vivo. Interestingly, the severity of behavioral changes correlates with the level of NL2 expression, suggesting dose-dependent changes in synapse function and behavior. The lack of related abnormalities in TgNL1 further suggest that the observed behavioral changes in TgNL2 mice resulted from alterations in synaptic maturation and/or function attributable to specific manipulation of NL2 levels in vivo. Importantly, neither TgNL1 nor TgNL2 strains display (Graf et al., 2004). deficits in basic sensory, reflexive, or motor function using the modified SHIRPA screen, making them feasible candidates for additional behavioral characterization. Intact motor function and exploratory motivation was further confirmed in TgNL2 mice in open field, elevated plus, and social approach tasks in which no deficits were observed in control measures of speed, distance traveled, or total entries.

The differential enrichment of specific NLs to particular synaptic sites in vivo suggests that NL3 and NL4 mainly modulate excitatory synaptic function, whereas NL2 is associated with modulation of inhibitory synaptic transmission (Song et al., 1999; Dean et al., 2003; Prange et al., 2004; Varoqueaux et al., 2004, 2006; Chubykin et al., 2005, 2007; Levinson and El-Husseini, 2005; Levinson et al., 2005; Sara et al., 2005; Dean and Dresbach, 2006). In particular, loss of NL2 has been shown to specifically alter inhibitory synapse function in vivo. Consistent with these findings, our results show that enhanced expression of NL2 results in a significant increase in inhibitory synapse maturation and transmission in cortical areas. However, it is important to note that a small but significant change in excitatory synapse morphology was also observed in TgNL2 mice, indicating that NL2 expression can influence both excitatory and inhibitory contact maturation, although with pronounced effects on inhibitory contacts. These data suggest that NL2 function in vivo is not fully restricted to inhibitory synapse maturation. These findings also hint to some overlapping and redundant functions of members of the NL family in vivo. In support of some functional redundancy between NLs, knock-out of NL1-NL3 is lethal, whereas all of the single and double knock-out combinations are viable (Varoqueaux et al., 2006). The finding that endogenous NL2 is found at $\sim 20-30 \%$ of excitatory synapses and the recent work that demonstrates that NLs can form heteroligomers (Budreck and Scheiffele, 2007) lend additional support to this notion.

The mechanism underlying the lack of change in inhibitory postsynaptic responses remains unclear. It is possible that recruitment of GABA receptors at inhibitory synapses is more constrained and consequently the presynaptic changes seen did not lead to an increase in recruitment of postsynaptic GABA receptors. This could be caused by enhanced levels of NL2, which can act to disperse GABA receptors and reduce inhibitory currents

The changes observed including limb clasping, repetitive behaviors, anxiety, and social dysfunction are similar to those observed in animal models of Rett syndrome (Chen et al., 2001; Guy et al., 2001; Shahbazian et al., 2002; Pelka et al., 2006). Some of 
these phenotypic characteristics also resemble aspects of human disorders, including Rett syndrome and autism (Hagberg, 2002; Rubenstein and Merzenich, 2003; Zoghbi, 2003; Dover and Le Couteur, 2007; Lewis et al., 2007). Autism, a genetically linked disorder, is characterized by varying degrees of abnormality in communication ability, social interactions, repetitive and stereotyped behavior, as well as high incidence of seizure (Tuchman and Rapin, 2002; Rubenstein and Merzenich, 2003; Zoghbi, 2003; Christ et al., 2007; Dover and Le Couteur, 2007; Rutherford et al., 2007).

Of particular interest, recent studies have shown rearrangement of chromosomal regions harboring NL1 and NL2, as well as mutations in NL3 and NL4 in families with autism (Konstantareas and Homatidis, 1999; Auranen et al., 2002; Jamain et al., 2003; Laumonnier et al., 2004; Lisé and El-Husseini, 2006). A single-copy chromosomal deletion of a region containing $\alpha / \beta$-Nrxs indicates that altered amounts of these proteins is sufficient to confer the behavioral changes associated with autism (Szatmari et al., 2007). In addition to single gene alterations, recent studies have shown that many autistic patients have novel deletions and duplications in their genomes (Sebat et al., 2007).

Neuroimaging and postmortem studies of patients with autism suggest that an alteration in the ratio of $\mathrm{E} / \mathrm{I}$ in neural circuits underlies the dysfunctions characteristic of autism (Rubenstein and Merzenich, 2003). The theory proposed by Rubenstein and Merzenich suggests that the dysfunction in autism could result from a shift toward excitation, but, in mouse models of related disorders such as Rett syndrome (Dani et al., 2005), the trend appears to favor inhibition. In addition, increased inhibition was observed in mice expressing an autism-related mutation of NL3, and this was shown to result in altered social interaction (Tabuchi et al., 2007). In this regard, a gain of NL2 function may result in a shift toward increased inhibition, mimicking the reduced function of the mutant forms of NL3 or NL4 most commonly associated with autism. Thus, as also observed for models of Rett syndrome (Collins et al., 2004; Gemelli et al., 2006), both reduced and enhanced expression of affected genes may model the underlying cause of neurodevelopmental disorders such as autism.

Several lines of evidence indicate multiple deficits in the structure and function of the brain in individuals with autism. In particular, there is strong evidence supporting that abnormalities in the frontal cortex and the amygdala contribute highly to deficits in social behavior and anxiety. In particular, previous studies have shown a link between increased excitation in the amygdala and anxiety (Davis et al., 1994). Amygdala excitability can also be increased via disinhibition (decreasing inhibitory transmission $n=8$.
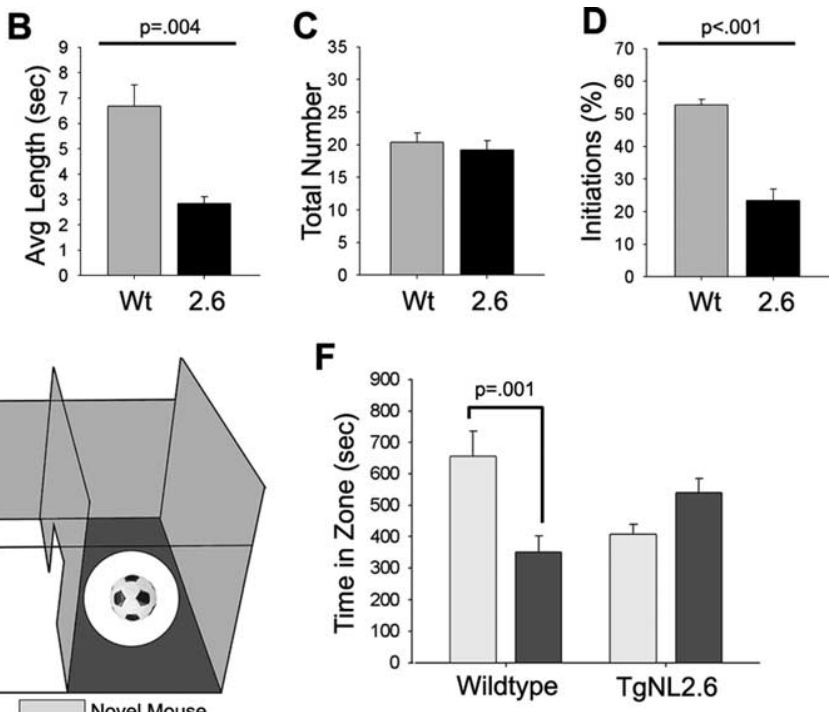

Figure 7. Deficits in social interactions in mice expressing neuroligin 2. A, Assessment of the total time wild-type or TgNL2.6 a 5 min period. $\boldsymbol{B}$, Graph showing the average length of individual interactions between wild-type or TgNL2.6 mice and a novel mouse (WT, $6.68 \pm 0.84 ;$ TgNL2.6, $2.84 \pm 0.26 ; t$ test, $p=0.004)$. C, No difference was observed in the total number of interactions (WT, $20.40 \pm 1.40 ; \operatorname{TgNL2} .6,19.20 \pm 1.41 ; t$ test, $p=0.527$ ) between wild-type or TgNL2.6 mice and novel mice. , Proportion of interactions initiated by either wild-type or TgNL2.6 mice with a novel mouse (WT, $52.80 \pm 1.67 ; \operatorname{TgNL2} .6$, $<0.001$. $\boldsymbol{E}$, Schematic of the three-chambered social behavior apparatus. $\boldsymbol{F}$, Analysis of time spent (WT novel mouse, $654.78 \pm$ TgNL2.6 novel object) in the novel mouse and novel object chambers of the social apparatus. G. Frequency of rearing (active exploration) in the chambers of the social apparatus (WT novel mouse, $115.50 \pm 23.61$; WT novel object, $59.50 \pm 7.84$; TgNL2.6 novel mouse, $94.00 \pm 12.20$; TgNL2.6 novel object, $89.50 \pm 8.44 ;$ ANOVA, $F_{(3,28)}=2.54, p=0.077 ;$ post hoc tests, $p=0.011$ WT novel mouse vs WT novel object, $p=0.828 \mathrm{TgNL2} .6$ novel mouse vs TgNL2.6 novel object). Data shown are means \pm SEMs. Reciprocal social interaction, wild type and $\operatorname{TgNL2.6,n}=10$; three-chamber social approach behavior, wild type and TgNL2.6,

from other brain regions). For instance, increased inhibition within the prefrontal cortex, which normally acts to inhibit the amygdala (Rosenkranz et al., 2003; Quirk and Gehlert, 2003; Quirk et al., 2003), can lead to increased excitation (disinhibition) in the amygdala and, hence, anxiety (Davis et al., 1994; Berkowitz et al., 2007; Bishop, 2007). Changes in the morphology and density of inhibitory synapses and increases in mIPSC frequency in the frontal cortex observed in the present work may therefore disinhibit the amygdala and contribute, at least in part, to the enhanced anxiety in TgNL2 mice. In relation to altered frontal cortex-amygdala projections, our data may also shed light on a hypothesis that suggests that the dysfunction in autism may result from excessive and unselective connectivity in local frontal cortex circuitry, paired with impoverished long-range connectivity to other systems such as the amygdala (Courchesne and Pierce, 2005). 
A

Wildtype

Neck EMG

Left FP EEG

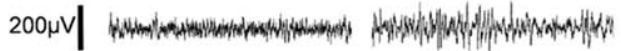

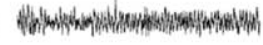

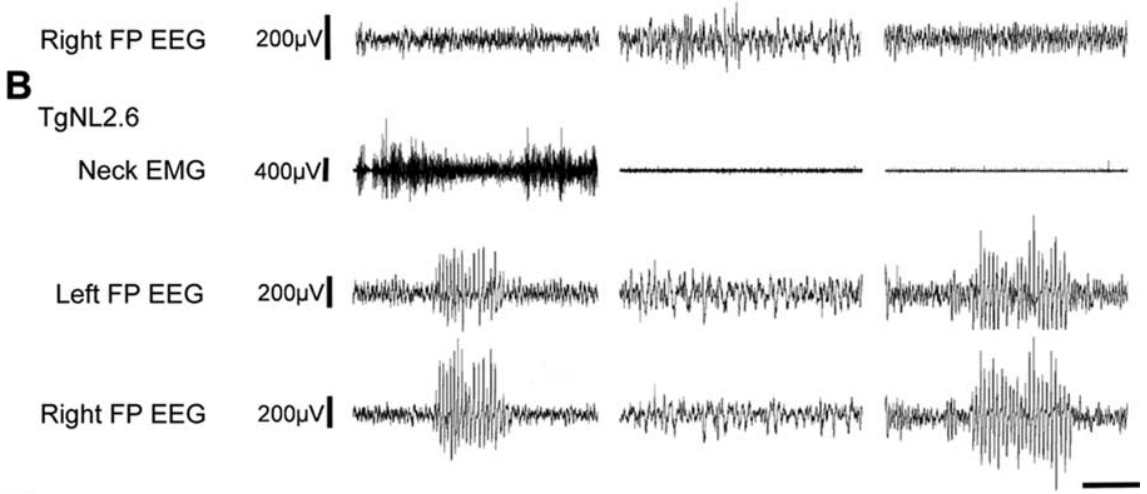

C

\begin{tabular}{|c|c|r|r|c|}
\hline Animal ID & $\begin{array}{c}\text { Avgerage } \\
\text { Duration }\end{array}$ & $\begin{array}{c}\text { Number per } \\
\text { Hour }\end{array}$ & $\begin{array}{c}\text { Spikes per } \\
\text { Second }\end{array}$ & State \\
\hline $62-10$ & 1.4 & 1.7 & 8.22 & NREM, REM \\
\hline $62-9$ & 1.7 & 2.0 & 7.66 & NREM, REM \\
\hline $58-6$ & 1.2 & 3.0 & 7.46 & wake \\
\hline $63-5$ & 1.5 & 10.0 & 7.86 & wake, REM \\
\hline $60-5$ & 1.7 & 13.3 & 7.30 & wake, REM \\
\hline $60-6$ & 1.9 & 16.0 & 6.03 & wake, REM \\
\hline $57-8$ & 1.9 & 18.3 & 7.95 & wake \\
\hline $60-8$ & 2.0 & 26.0 & 6.95 & wake, REM \\
\hline \multicolumn{5}{|c|}{} \\
\hline Mean & 1.7 & 11.3 & 7.43 & \\
\hline SEM \pm & 0.2 & 2.9 & 1.06 & \\
\hline
\end{tabular}

Figure 8. Seizure spiking activity as observed via freely moving EEG recording in mice expressing NL2. $A, B$, Representative traces of differential recordings from neck EMG and left and right frontoparietal (FP) EEG from wild-type $(\boldsymbol{A})$ and TgNL2 (B) mice. TgNL2 mice exhibit bilaterally synchronous bursting activity characterized by spike-wave discharge $\sim 7 \mathrm{~Hz}$. C, Spiking activity was observed in 8 of $10 \mathrm{TgNL} 2$ mice tested and was detected in all stages of sleep but most consistently in wakefulness and rapid eye movement sleep. REM, Rapid eye movement; NREM, non-rapid eye movement.

The incidence of frontoparietal seizure spiking, in light of increased prefrontal cortex inhibition, is particularly interesting because prevailing theories suggest that seizure activity results from hypersynchronous neuronal activity and is commonly associated with increased E/I ratios (Kofke et al., 1997; Stief et al., 2007). However, recent reports have also shown that focal seizure activity can result from desynchronization of firing caused by increased inhibitory feedback (Netoff and Schiff, 2002; Mormann et al., 2003; Klaassen et al., 2006). Thus, increased inhibition observed in frontal cortex of TgNL2 mice could underlie the cortical seizure spiking activity detected by freely moving EEG recording.

Clinically apparent seizures occur in $\sim 30 \%$ of autistic individuals (Gillberg and Billstedt, 2000), whereas 50-70\% of autistic individuals display ongoing "sharp-spike" activity during sleep (Lewine et al., 1999; Wheless et al., 2002). The incidence of seizure spiking in TgNL2 mice may relate to cortical-limbic dysfunction discussed above in relation to autism, which is also implicated in temporal lobe epilepsy (Aroniadou-Anderjaska et al., 2007). In keeping with the idea of frontal cortex inhibition leading to amygdala disinhibition in TgNL2 mice, altered neuronal excitability in the amygdala could generate spontaneous epilep- tiform activity, which will subsequently spread to the other brain areas (Aroniadou-Anderjaska et al., 2007). Overall, the spiking activity observed may be directly attributable to alterations in cortical synchrony cause by increased inhibition or indirectly as a result of overexcitation in the amygdala spreading to the cortex. Future studies are needed to determine whether enhanced inhibition in the frontal cortex can be related to alterations in the excitability of the amygdala.

Our new findings combined with the link between mutations in NLs/Nrxs and autism may provide the neuronal basis for alterations in neuronal excitability, seizure spiking activity, stereotypies, anxiety, and impaired social interactions associated with autism (Konstantareas and Homatidis, 1999; Auranen et al., 2002; Jamain et al., 2003; Laumonnier et al., 2004; Lisé and El-Husseini, 2006; Szatmari et al., 2007). In conclusion, we have discovered synapse and behavioral abnormalities in mice with altered expression of particular members of the NL family that recapitulate multiple aspects of behavioral changes associated with neurodevelopmental disorders such as Rett syndrome and autism. These include impaired social interactions, stereotyped patterns of behavior, and enhanced incidence of seizure spiking, as depicted by EEG analysis in freely moving animals. We also show that a small change in NL2 expression results in synaptic abnormalities in cortical networks, which are thought to underlie the complex behavioral alterations seen in autism. These findings may provide the neural basis for synaptic imbalance and altered behavior associated with autism.

\section{References}

Aroniadou-Anderjaska V, Qashu F, Braga MF (2007) Mechanisms regulating GABAergic inhibitory transmission in the basolateral amygdala: implications for epilepsy and anxiety disorders. Amino Acids 32:305-315.

Auranen M, Vanhala R, Varilo T, Ayers K, Kempas E, Ylisaukko-Oja T, Sinsheimer JS, Peltonen L, Järvelä I (2002) A genomewide screen for autism-spectrum disorders: evidence for a major susceptibility locus on chromosome 3q25-27. Am J Hum Genet 71:777-790.

Belzung C, Misslin R, Vogel E, Dodd RH, Chapouthier G (1987) Anxiogenic effects of methyl-beta-carboline-3-carboxylate in a light/dark choice situation. Pharmacol Biochem Behav 28:29-33.

Berkowitz RL, Coplan JD, Reddy DP, Gorman JM (2007) The human dimension: how the prefrontal cortex modulates the subcortical fear response. Rev Neurosci 18:191-207.

Bishop SJ (2007) Neurocognitive mechanisms of anxiety: an integrative account. Trends Cogn Sci 11:307-316.

Boucard AA, Chubykin AA, Comoletti D, Taylor P, Südhof TC (2005) A splice code for trans-synaptic cell adhesion mediated by binding of neuroligin 1 to alpha- and beta-neurexins. Neuron 48:229-236.

Bourin M, Hascoët M (2003) The mouse light/dark box test. Eur J Pharmacol 463:55-65.

Brown SD, Chambon P, de Angelis MH (2005) EMPReSS: standardized phenotype screens for functional annotation of the mouse genome. Nat Genet 37:1155. 
Brown SD, Hancock JM, Gates H (2006) Understanding mammalian genetic systems: the challenge of phenotyping in the mouse. PLoS Genet 2:e118.

Budreck EC, Scheiffele P (2007) Neuroligin-3 is a neuronal adhesion protein at GABAergic and glutamatergic synapses. Eur J Neurosci 26:1738-1748.

Chen RZ, Akbarian S, Tudor M, Jaenisch R (2001) Deficiency of methylCpG binding protein-2 in CNS neurons results in a Rett-like phenotype in mice. Nat Genet 27:327-331.

Chih B, Engelman H, Scheiffele P (2005) Control of excitatory and inhibitory synapse formation by neuroligins. Science 307:1324-1328.

Chih B, Gollan L, Scheiffele P (2006) Alternative splicing controls selective trans-synaptic interactions of the neuroligin-neurexin complex. Neuron 51:171-178.

Christ SE, Holt DD, White DA, Green L (2007) Inhibitory control in children with autism spectrum disorder. J Autism Dev Disord 37:1155-1165.

Chubykin AA, Liu X, Comoletti D, Tsigelny I, Taylor P, Südhof TC (2005) Dissection of synapse induction by neuroligins: effect of a neuroligin mutation associated with autism. J Biol Chem 280:22365-22374.

Chubykin AA, Atasoy D, Etherton MR, Brose N, Kavalali ET, Gibson JR, Südhof TC (2007) Activity-dependent validation of excitatory versus inhibitory synapses by neuroligin-1 versus neuroligin-2. Neuron 54:919-931.

Cline H (2005) Synaptogenesis: a balancing act between excitation and inhibition. Curr Biol 15:R203-R205.

Collins AL, Levenson JM, Vilaythong AP, Richman R, Armstrong DL, Noebels JL, David Sweatt J, Zoghbi HY (2004) Mild overexpression of $\mathrm{MeCP} 2$ causes a progressive neurological disorder in mice. Hum Mol Genet 13:2679-2689.

Courchesne E, Pierce K (2005) Why the frontal cortex in autism might be talking only to itself: local over-connectivity but long-distance disconnection. Curr Opin Neurobiol 15:225-230.

Dani VS, Chang Q, Maffei A, Turrigiano GG, Jaenisch R, Nelson SB (2005) Reduced cortical activity due to a shift in the balance between excitation and inhibition in a mouse model of Rett syndrome. Proc Natl Acad Sci USA 102:12560-12565.

Davis M, Rainnie D, Cassell M (1994) Neurotransmission in the rat amygdala related to fear and anxiety. Trends Neurosci 17:208-214.

Dean C, Dresbach T (2006) Neuroligins and neurexins: linking cell adhesion, synapse formation and cognitive function. Trends Neurosci 29:21-29.

Dean C, Scholl FG, Choih J, DeMaria S, Berger J, Isacoff E, Scheiffele P (2003) Neurexin mediates the assembly of presynaptic terminals. Nat Neurosci 6:708-716.

Dover CJ, Le Couteur A (2007) How to diagnose autism. Arch Dis Child 92:540-545.

Garber K (2007) Neuroscience. Autism's cause may reside in abnormalities at the synapse. Science 317:190-191.

Garner JP (2005) Stereotypies and other abnormal repetitive behaviors: potential impact on validity, reliability, and replicability of scientific outcomes. Ilar J 46:106-117.

Garner JP, Mason GJ (2002) Evidence for a relationship between cage stereotypies and behavioural disinhibition in laboratory rodents. Behav Brain Res 136:83-92.

Gemelli T, Berton O, Nelson ED, Perrotti LI, Jaenisch R, Monteggia LM (2006) Postnatal loss of methyl-CpG binding protein 2 in the forebrain is sufficient to mediate behavioral aspects of Rett syndrome in mice. Biol Psychiatry 59:468-476.

Gerrow K, Romorini S, Nabi SM, Colicos MA, Sala C, El-Husseini A (2006) A preformed complex of postsynaptic proteins is involved in excitatory synapse development. Neuron 49:547-562.

Gillberg C, Billstedt E (2000) Autism and Asperger syndrome: coexistence with other clinical disorders. Acta Psychiatr Scand 102:321-330.

Graf ER, Zhang X, Jin SX, Linhoff MW, Craig AM (2004) Neurexins induce differentiation of GABA and glutamate postsynaptic specializations via neuroligins. Cell 119:1013-1026.

Graf ER, Kang Y, Hauner AM, Craig AM (2006) Structure function and splice site analysis of the synaptogenic activity of the neurexin- $1 \beta$ LNS domain. J Neurosci 26:4256-4265.

Guy J, Hendrich B, Holmes M, Martin JE, Bird A (2001) A mouse Mecp2null mutation causes neurological symptoms that mimic Rett syndrome. Nat Genet 27:322-326.
Hagberg B (2002) Clinical manifestations and stages of Rett syndrome. Ment Retard Dev Disabil Res Rev 8:61-65.

Hascoët M, Bourin M (1998) A new approach to the light/dark test procedure in mice. Pharmacol Biochem Behav 60:645-653.

Holmes A, Yang RJ, Crawley JN (2002) Evaluation of an anxiety-related phenotype in galanin overexpressing transgenic mice. J Mol Neurosci $18: 151-165$.

Holmes A, Kinney JW, Wrenn CC, Li Q, Yang RJ, Ma L, Vishwanath J, Saavedra MC, Innerfield CE, Jacoby AS, Shine J, Iismaa TP, Crawley JN (2003) Galanin GAL-R1 receptor null mutant mice display increased anxiety-like behavior specific to the elevated plus-maze. Neuropsychopharmacology 28:1031-1044.

Holmes GL, McCabe B (2001) Brain development and generation of brain pathologies. Int Rev Neurobiol 45:17-41.

Ichtchenko K, Hata Y, Nguyen T, Ullrich B, Missler M, Moomaw C, Südhof TC (1995) Neuroligin 1: a splice site-specific ligand for beta-neurexins. Cell 81:435-443.

Irie M, Hata Y, Takeuchi M, Ichtchenko K, Toyoda A, Hirao K, Takai Y, Rosahl TW, Südhof TC (1997) Binding of neuroligins to PSD-95. Science 277:1511-1515.

Jamain S, Quach H, Betancur C, Råstam M, Colineaux C, Gillberg IC, Soderstrom H, Giros B, Leboyer M, Gillberg C, Bourgeron T (2003) Mutations of the $\mathrm{X}$-linked genes encoding neuroligins NLGN3 and NLGN4 are associated with autism. Nat Genet 34:27-29.

Karler R, Calder LD, Thai LH, Bedingfield JB (1995) The dopaminergic, glutamatergic, GABAergic bases for the action of amphetamine and cocaine. Brain Res 671:100-104.

Karler R, Bedingfield JB, Thai DK, Calder LD (1997) The role of the frontal cortex in the mouse in behavioral sensitization to amphetamine. Brain Res 757:228-235.

Klaassen A, Glykys J, Maguire J, Labarca C, Mody I, Boulter J (2006) Seizures and enhanced cortical GABAergic inhibition in two mouse models of human autosomal dominant nocturnal frontal lobe epilepsy. Proc Natl Acad Sci USA 103:19152-19157.

Kofke WA, Tempelhoff R, Dasheiff RM (1997) Anesthetic implications of epilepsy, status epilepticus, and epilepsy surgery. J Neurosurg Anesthesiol 9:349-372.

Konstantareas MM, Homatidis S (1999) Chromosomal abnormalities in a series of children with autistic disorder. J Autism Dev Disord 29:275-285.

Laumonnier F, Bonnet-Brilhault F, Gomot M, Blanc R, David A, Moizard MP, Raynaud M, Ronce N, Lemonnier E, Calvas P, Laudier B, Chelly J, Fryns JP, Ropers HH, Hamel BC, Andres C, Barthélémy C, Moraine C, Briault S (2004) X-linked mental retardation and autism are associated with a mutation in the NLGN4 gene, a member of the neuroligin family. Am J Hum Genet 74:552-557.

Levinson JN, El-Husseini A (2005) Building excitatory and inhibitory synapses: balancing neuroligin partnerships. Neuron 48:171-174.

Levinson JN, Chéry N, Huang K, Wong TP, Gerrow K, Kang R, Prange O, Wang YT, El-Husseini A (2005) Neuroligins mediate excitatory and inhibitory synapse formation: involvement of PSD-95 and neurexin-1beta in neuroligin-induced synaptic specificity. J Biol Chem 280:17312-17319.

Lewine JD, Andrews R, Chez M, Patil AA, Devinsky O, Smith M, Kanner A, Davis JT, Funke M, Jones G, Chong B, Provencal S, Weisend M, Lee RR, Orrison Jr WW (1999) Magnetoencephalographic patterns of epileptiform activity in children with regressive autism spectrum disorders. Pediatrics 104:405-418.

Lewis MH, Tanimura Y, Lee LW, Bodfish JW (2007) Animal models of restricted repetitive behavior in autism. Behav Brain Res 176:66-74.

Lisé MF, El-Husseini A (2006) The neuroligin and neurexin families: from structure to function at the synapse. Cell Mol Life Sci 63:1833-1849.

Mormann F, Kreuz T, Andrzejak RG, David P, Lehnertz K, Elger CE (2003) Epileptic seizures are preceded by a decrease in synchronization. Epilepsy Res 53:173-185.

Moy SS, Nadler JJ, Perez A, Barbaro RP, Johns JM, Magnuson TR, Piven J, Crawley JN (2004) Sociability and preference for social novelty in five inbred strains: an approach to assess autistic-like behavior in mice. Genes Brain Behav 3:287-302.

Nadler JJ, Moy SS, Dold G, Trang D, Simmons N, Perez A, Young NB, Barbaro RP, Piven J, Magnuson TR, Crawley JN (2004) Automated apparatus for quantitation of social approach behaviors in mice. Genes Brain Behav 3:303-314. 
Netoff TI, Schiff SJ (2002) Decreased neuronal synchronization during experimental seizures. J Neurosci 22:7297-7307.

Pelka GJ, Watson CM, Radziewic T, Hayward M, Lahooti H, Christodoulou J, Tam PP (2006) Mecp2 deficiency is associated with learning and cognitive deficits and altered gene activity in the hippocampal region of mice. Brain 129:887-898.

Powell SB, Newman HA, Pendergast JF, Lewis MH (1999) A rodent model of spontaneous stereotypy: initial characterization of developmental, environmental, and neurobiological factors. Physiol Behav 66:355-363.

Prange O, Wong TP, Gerrow K, Wang YT, El-Husseini A (2004) A balance between excitatory and inhibitory synapses is controlled by PSD-95 and neuroligin. Proc Natl Acad Sci USA 101:13915-13920.

Quirk GJ, Gehlert DR (2003) Inhibition of the amygdala: key to pathological states? Ann NY Acad Sci 985:263-272.

Quirk GJ, Likhtik E, Pelletier JG, Paré D (2003) Stimulation of medial prefrontal cortex decreases the responsiveness of central amygdala output neurons. J Neurosci 23:8800-8807.

Rosenkranz JA, Moore H, Grace AA (2003) The prefrontal cortex regulates lateral amygdala neuronal plasticity and responses to previously conditioned stimuli. J Neurosci 23:11054-11064.

Rubenstein JL, Merzenich MM (2003) Model of autism: increased ratio of excitation/inhibition in key neural systems. Genes Brain Behav 2:255-267.

Rutherford MD, Clements KA, Sekuler AB (2007) Differences in discrimination of eye and mouth displacement in autism spectrum disorders. Vision Res 47:2099-2110.

Sara Y, Biederer T, Atasoy D, Chubykin A, Mozhayeva MG, Südhof TC, Kavalali ET (2005) Selective capability of SynCAM and neuroligin for functional synapse assembly. J Neurosci 25:260-270.

Scheiffele P, Fan J, Choih J, Fetter R, Serafini T (2000) Neuroligin expressed in nonneuronal cells triggers presynaptic development in contacting axons. Cell 101:657-669.

Sebat J, Lakshmi B, Malhotra D, Troge J, Lese-Martin C, Walsh T, Yamrom B, Yoon S, Krasnitz A, Kendall J, Leotta A, Pai D, Zhang R, Lee YH, Hicks J, Spence SJ, Lee AT, Puura K, Lehtimäki T, Ledbetter D, et al. (2007) Strong association of de novo copy number mutations with autism. Science 316:445-449.

Shahbazian M, Young J, Yuva-Paylor L, Spencer C, Antalffy B, Noebels J, Armstrong D, Paylor R, Zoghbi H (2002) Mice with truncated MeCP2 recapitulate many Rett syndrome features and display hyperacetylation of histone H3. Neuron 35:243-254.

Song JY, Ichtchenko K, Südhof TC, Brose N (1999) Neuroligin 1 is a postsynaptic cell-adhesion molecule of excitatory synapses. Proc Natl Acad Sci USA 96:1100-1105.

Stief F, Zuschratter W, Hartmann K, Schmitz D, Draguhn A (2007) Enhanced synaptic excitation-inhibition ratio in hippocampal interneurons of rats with temporal lobe epilepsy. Eur J Neurosci 25:519-528.

Szatmari P, Paterson AD, Zwaigenbaum L, Roberts W, Brian J, Liu XQ, Vincent JB, Skaug JL, Thompson AP, Senman L, Feuk L, Qian C, Bryson SE, Jones MB, Marshall CR, Scherer SW, Vieland VJ, Bartlett C, Mangin LV, Goedken R, et al. (2007) Mapping autism risk loci using genetic linkage and chromosomal rearrangements. Nat Genet 39:319-328.

Tabuchi K, Blundell J, Etherton MR, Hammer RE, Liu X, Powell CM, Südhof TC (2007) A neuroligin-3 mutation implicated in autism increases inhibitory synaptic transmission in mice. Science 318:71-76.

Tuchman R, Rapin I (2002) Epilepsy in autism. Lancet Neurol 1:352-358.

Turner CA, Presti MF, Newman HA, Bugenhagen P, Crnic L, Lewis MH (2001) Spontaneous stereotypy in an animal model of Down syndrome: Ts65Dn mice. Behav Genet 31:393-400.

Turrigiano GG, Nelson SB (2004) Homeostatic plasticity in the developing nervous system. Nat Rev Neurosci 5:97-107.

Varoqueaux F, Jamain S, Brose N (2004) Neuroligin 2 is exclusively localized to inhibitory synapses. Eur J Cell Biol 83:449-456.

Varoqueaux F, Aramuni G, Rawson RL, Mohrmann R, Missler M, Gottmann K, Zhang W, Südhof TC, Brose N (2006) Neuroligins determine synapse maturation and function. Neuron 51:741-754.

Waites CL, Craig AM, Garner CC (2005) Mechanisms of vertebrate synaptogenesis. Annu Rev Neurosci 28:251-274.

Wheless JW, Simos PG, Butler IJ (2002) Language dysfunction in epileptic conditions. Semin Pediatr Neurol 9:218-228.

Wisden W, Morris BJ (2002) In situ hybridization with oligonucleotide probes. Int Rev Neurobiol 47:3-59.

Wu LJ, Ko SW, Toyoda H, Zhao MG, Xu H, Vadakkan KI, Ren M, Knifed E, Shum F, Quan J, Zhang XH, Zhuo M (2007) Increased anxiety-like behavior and enhanced synaptic efficacy in the amygdala of GluR5 knockout mice. PLoS ONE 2:e167.

Würbel H (2001) Ideal homes? Housing effects on rodent brain and behaviour. Trends Neurosci 24:207-211.

Würbel H, Stauffacher M (1996) Prevention of stereotypy in laboratory mice: effects on stress physiology and behaviour. Physiol Behav 59:1163-1170.

Zoghbi HY (2003) Postnatal neurodevelopmental disorders: meeting at the synapse? Science 302:826-830. 